\title{
Biochemical status of the sow body with the use of vitamin and mineral supplement in the diet
}

\author{
A.A. Ovchinnikov ${ }^{1,}$,, L.Yu. Ovchinnikova ${ }^{1}, Y u . V$. Matrosova $^{1}, D . S$. Bryukhanov $^{1}$, and E.A. \\ Babich $^{2}$ \\ ${ }^{1}$ FSBEU HE South-Ural SAU, Troitsk, Russia \\ ${ }^{2}$ ACES of LLP "Zarechnoye", Kostanay, Kazakhstan
}

\begin{abstract}
The diet of monogastric animals should be adjusted for vitamin and mineral nutrition during the period of growing and economic use. They affect all types of metabolism, especially in the last third of gestation of sows and the development of young pigs in the postnatal period. For sows throughout the period of gestation and suckling, it is important to include in the diet such biogenic element as folic acid, as well as a set of essential trace elements (copper, zinc, cobalt, manganese) and group B vitamins, the use of which during the entire production cycle helped to improve prolificacy of sows by $15.2 \%$, the average increase was $8.8 \%$ and the safety of young pigs dairy period of cultivation is $7.2 \%$, which reduced the cost of feed for growing one reared pig by 10.6-18.1\%.
\end{abstract}

\section{Introduction}

The animal's body is a complex multi-functional system in which processes occur from feed intake, conversion of nutrients to organs, tissues and developing fetus, resulting products. At the same time, the control of all stages of the state of organs and systems is neurohumoral and depends on many factors of the external and internal environment. In particular, on the work of the endocrine glands that produce enzymes, the activity of which depends on the completeness of hydrolysis of feed nutrients and the degree of their absorption by the body.

Biologically active substances contained in feed and coming as part of the premix of complete compound feed should fill, first of all, the deficit of this nutrition element, and if in case of excess, it should not have a negative effect on the metabolism [6,7]. The quantitative content of vitamins normalized in the daily norm of feed sometimes does not meet their needs. The result is a growing backlog of young growth, increased service period and index of cattle insemination, newborn calves have immature organs and systems. For ruminants, most vitamins enter the body with a variety of feed groups and meet their needs, for pigs with industrial production technology and concentrate type of feeding, their introduction is required due to the premix. The traditional inclusion of retinol, tocopherol, and ergocalceferol in the diet is not enough, and additional administration of such a vitamin

*Corresponding author: tvi_t@mail.ru 
as folic acid is necessary, which affects the reproductive functions of breeding stock [1214]. However, the norm of vitamin nutrition of pigs has not yet been fully studied. It depends on many factors and, above all, the state of the body, diet and keeping conditions. Accordingly, the quantitative content of vitamins, especially group B, for pigs is subject to adjustment, most often in the direction of increase.

If vitamins in the body act as catalysts for metabolic processes, then biogenic microelements are part of many enzymatic systems and without their participation, the digestive process may be at an insufficient level [3, 10, 11, 15]. It should be said that without zinc, the functional activity of the pancreas decreases, manganese - redox processes in the liver, cobalt - hematopoietic processes, copper - cellular respiration. These microelements are introduced into the premix of the diet in the form of mineral salts, although the most digestible form is organic, in the form of chelated organic complexes. Unfortunately, their use by the domestic feed industry is not high enough.

The standard approach to the regulation of trace elements in the diet of farm animals limits the realization of genetic potential, leads to an increase in production costs and a decrease in the profitability of production. When calculating the need for a separate mineral element of nutrition, it is necessary to take into account the territorial affiliation with the presence of the actual content of biogenic elements in the soil, water and feed, as well as the presence of antagonists that reduce the biological effect of each element. In this case, the importance of quality control of complete feed for the presence of each normalized element in them increases. However, no matter how complete the feed is, endogenous factors of the digestive process can negatively affect the absorption of a particular mineral element. In this regard, the most accurate control method is a biochemical blood test, which allows to adjust the feeding diet for the presence of mineral elements in it.

Therefore, the goal was to compare the biochemical status of sows and their reproductive functions when dietary supplements such as folic acid, complex vitamin supplement Hexavit and a set of biogenic microelements were included in the diet. The research tasks were to assess the morpho-biochemical parameters of sow blood during various periods of gestation, to determine the influence of the studied factor on the reproductive functions, growth and safety of young pigs during the dairy growing period, and to calculate the feed costs per reared pig of weaning age.

\section{Material and methods}

The research was conducted in the conditions of the pig complex LLC "Agrofirma Ariant" on four groups of pregnant sows, 15 heads each. When forming animals into groups, generally accepted guidelines were used that provide for single-breed animals, live weight, physiological condition, age and number of farrowing, conditions of maintenance and service.

Against the background of the main ration of feeding with complete-ration feed SK-1 for pregnant and SK-2 for suckling sows, and SK-3 for young pigs of the lactating period of rearing, the livestock of the experimental groups additionally received folic acid in the amount of $35 \mathrm{mg}$ per head per day and a set of trace elements of copper, zinc, cobalt, manganese from 10 to $50 \mathrm{mg}$ per $100 \mathrm{~kg}$ of live weight (group II), complex vitamin preparation Hexavit - $196 \mathrm{mg} / \mathrm{head}$ per day and a set of trace elements copper, zinc, cobalt, manganese from 10 to $50 \mathrm{mg}$ per $100 \mathrm{~kg}$ of live weight (group III), folic acid, Hexavit and trace elements in a similar dosage were added to the diet of sows in group IV.

All experimental animals were kept in one sector during group maintenance, and in the subsequent survey in one sector, in individual quarters.

Biochemical blood tests of sows were performed in 5 heads from each group on the 84th and 110th days of gestation. Morpho-biochemical blood tests were performed 
according to generally accepted methods on certified and calibrated equipment. The trace element composition of blood samples was studied by atomic adsorption method.

Reproductive functions of sows were determined individually for each animal by the total number of young pigs born, live young pigs in the nest, their heavy litter, and live weight in 30 days. The safety of livestock was calculated by the number of piglets of weaning age and expressed as a percentage of the number of newborns.

Feed costs per reared pig were determined based on the feed actually fed for each group of sows and the weaned piglets received.

The resulting digital material was processed by the method of variational statistics with determination of the confidence level.

\section{Results and discussion}

The analysis of the sow feeding ration for the main nutrients showed (table 1) that it corresponds to the animals' nutritional needs.

Table 1. Concentration of nutrients in the dry matter of complete feed

\begin{tabular}{|l|c|c|c|}
\hline \multirow{2}{*}{ Indicator } & \multicolumn{3}{|c|}{ Complete feed } \\
\cline { 2 - 4 } & SK-1 & SK-2 & SK-3 \\
\hline Exchange energy, MJ & 140.5 & 152.1 & 159.1 \\
\hline Crude protein, \% & 16.1 & 19.8 & 20.5 \\
\hline Raw fiber, \% & 6.8 & 6.2 & 4.0 \\
\hline Lysine, \% & 0.78 & 1.07 & 1.59 \\
\hline Methionine+cystine, \% & 0.63 & 0.71 & 0.96 \\
\hline Calcium & 0.77 & 0.96 & 1.02 \\
\hline Phosphorus, \% & 0.66 & 0.69 & 0.64 \\
\hline
\end{tabular}

Blood testing of sows in the first two-thirds of gestation (84 days) showed (table 2 ) that with the addition of Hexavit and all the tested components to the diet of animals of group III and IV, there was a tendency to increase of hemoglobin in the blood by 4.2 and $6.3 \%$, in the last third of pregnancy - in group II and III by 3.2 and $7.5 \%$, respectively, and in group IV - decreased by $8.6 \%$. Significant differences in the content of erythrocytes between groups by period of gestation was not observed, and the number of leukocytes in the experimental groups compared to the control decreased during the first two-thirds of gestation by $15.2 \%$ in group II, $25.8 \%$ - in the III and by $31.0 \%$ in group IV, in the last third of gestation, respectively, $17.7 \%$ and $19.4 \%(\mathrm{P} \leq 0.05)$ and $24.5 \%(\mathrm{P} \leq 0.001)$.

Table 2. Hematological parameters of sows $\left(\mathrm{X} \pm \mathrm{m}_{\mathrm{x}}, \mathrm{n}=5\right)$

\begin{tabular}{|l|l|l|l|l|}
\hline \multirow{2}{*}{ Indicator } & \multicolumn{4}{c|}{ Group } \\
\cline { 2 - 5 } & \multicolumn{5}{|c|}{ I } & \multicolumn{1}{c|}{ II } & III & IV \\
\hline \multicolumn{5}{|c|}{ first $2 / 3$ of gestation } \\
\hline Hemoglobin, g/1 & $96.0 \pm 4.00$ & $84.0 \pm 8.00$ & $100.0 \pm 11.55$ & $102.0 \pm 14.00$ \\
\hline Red blood cells, $10^{12} / 1$ & $5.39 \pm 0.30$ & $4.72 \pm 0.38$ & $4.70 \pm 0.14$ & $6.34 \pm 0.47$ \\
\hline White blood cells, $10^{9} / 1$ & $12.00 \pm 1.80$ & $10.18 \pm 0.47$ & $8.90 \pm 0.49$ & $8.28 \pm 0.43$ \\
\hline \multicolumn{5}{|c|}{ last 1/3 of gestation } \\
\hline Hemoglobin, g/1 & $108.8 \pm 2.02$ & $112.3 \pm 3.50$ & $116.97 \pm 5.09$ & $99.40 \pm 5.12$ \\
\hline Red blood cells, $10^{12} / 1$ & $4.91 \pm 0.25$ & $5.02 \pm 0.17$ & $5.31 \pm 0.29$ & $4.50 \pm 0.21$ \\
\hline White blood cells, $10^{9} / 1$ & $14.04 \pm 0.66$ & $11.55 \pm 0.99$ & $11.31 \pm 1.03 *$ & $10.60 \pm 0.26^{* * *}$ \\
\hline
\end{tabular}

Here and further: *) $\mathrm{P} \leq 0.05 ; * *) \mathrm{P} \leq 0.01 ; * * *) \mathrm{P} \leq 0.001$. 
A decrease in the number of white blood cells in sows of the experimental groups during the gestation period indicates an increase in the body's defenses not due to cellular, but humoral immunity, which subsequently had a positive effect on the safety of the young pigs livestock.

The results of blood tests of sows on the content of individual biochemical parameters of the metabolism by period of gestation showed (table 3) that by the end of the first 84 days of gestation in the serum of animals of experimental groups there is a tendency of increasing the content of total protein in the group II by $5.5 \%$, III - by $3.8 \%$, in group IV by $10.4 \%$.

Table 3. Content of the main biochemical parameters in the blood of sows $\left(X \pm m_{x}, n=5\right)$

\begin{tabular}{|l|l|l|l|l|}
\hline \multirow{2}{*}{ Indicator } & \multicolumn{4}{c|}{ Group } \\
\cline { 2 - 5 } & \multicolumn{5}{|c|}{ I } & \multicolumn{1}{c|}{ II } & \multicolumn{1}{c|}{ III } & \multicolumn{1}{c|}{ IV } \\
\hline \multicolumn{5}{|c|}{ first $2 / 3$ of gestation } \\
\hline Total protein, g/1 & $90.5 \pm 4.3$ & $95.5 \pm 2.2$ & $93.9 \pm 3.6$ & $99.9 \pm 1.8$ \\
\hline Urea, mmol/1 & $14.47 \pm 0.33$ & $11.80 \pm 0.87^{*}$ & $12.63 \pm 2.98$ & $18.07 \pm 1.34^{*}$ \\
\hline Glucose, mmol/1 & $2.67 \pm 0.20$ & $3.91 \pm 0.21^{* *}$ & $3.91 \pm 0.21^{* *}$ & $4.32 \pm 0.62^{*}$ \\
\hline Total lipids, g/1 & $7.31 \pm 1.53$ & $11.29 \pm 0.67^{*}$ & $9.24 \pm 0.89$ & $9.57 \pm 0.24$ \\
\hline \multicolumn{5}{|c|}{ last $1 / 3$ of gestation } \\
\hline Total protein, g/1 & $86.0 \pm 0.09$ & $98.4 \pm 0.27^{* * *}$ & $82.8 \pm 0.16^{* * *}$ & $81.0 \pm 0.14^{* * *}$ \\
\hline Urea, mmol/1 & $6.32 \pm 0.26$ & $4.48 \pm 0.20^{* * *}$ & $2.68 \pm 0.09^{* * *}$ & $7.70 \pm 0.59^{*}$ \\
\hline Glucose, mmol/1 & $3.70 \pm 0.19$ & $3.89 \pm 0.32$ & $4.63 \pm 0.19^{* * *}$ & $5.18 \pm 0.49^{*}$ \\
\hline Total lipids, g/1 & $4.32 \pm 0.10$ & $3.18 \pm 0.50$ & $3.60 \pm 0.08^{* * *}$ & $4.54 \pm 0.36$ \\
\hline
\end{tabular}

However, with an increase in total protein, its best use is observed only in group II and III, where the urea content in comparison with the control group I decreased by $18.5 \%$ $(\mathrm{P} \leq 0.05)$ and $12.7 \%$, respectively, while in group IV, on the contrary, it increased by $24.9 \%$ $(\mathrm{P} \leq 0.05)$.

In the last third of gestation, only folic acid with trace elements in the diet of group II sows increased the level of total protein in the blood serum by $14.4 \%(\mathrm{P} 0.001)$ and reduced the loss of nitrogenous substances from the body, as evidenced by a decrease in urea levels in this group by $29.1 \%(\mathrm{P} \leq 0.001)$, while in group III and IV there was a decrease in the total protein content in the blood serum of sows by 3.7 and $5.8 \%(\mathrm{P} \leq 0.001)$. At the same time, the level of urea in group III decreased by $57.6 \%(\mathrm{P} \leq 0.001)$, and in group IV, on the contrary, its losses significantly increased by $21.8 \%(\mathrm{P} \leq 0.001)$.

During the entire gestation period the sows of the experimental groups had a higher level of energy metabolism, which is proved by glucose content in whole blood.

The intake of such an important plastic substance as lipids into the blood of sows indicates that if in the first two-thirds of gestation in group II compared to I, the difference in this metabolite was $44.6 \%$ ( $\mathrm{P} \leq 0.001$ ), in group III - only $26.4 \%$, in group IV $-30.9 \%$, in the last third of gestation, their level in group II and III of the experimental group decreased by 26.4 and $16.7 \%(\mathrm{P} \leq 0.001)$, while in group IV it was at the level of the control group.

The use of mineral feed additives in the diet of sows of the experimental groups affected their absorbtiob and blood intake (table 4). 
Table 4. Content of mineral elements in sows blood $\left(X \pm m_{x}, n=5\right)$

\begin{tabular}{|c|c|c|c|c|}
\hline \multirow[t]{2}{*}{ Indicator } & \multicolumn{4}{|c|}{ Group } \\
\hline & I & II & III & IV \\
\hline \multicolumn{5}{|c|}{ first $2 / 3$ of gestation } \\
\hline Calcium, mmol/1 & $2.65 \pm 0.39$ & $3.12 \pm 0.32$ & $3.12 \pm 0.24$ & $2.55 \pm 0.14$ \\
\hline Phosphorus, $\mathrm{mmol} / \mathrm{l}$ & $2.00 \pm 0.21$ & $1.68 \pm 0.32$ & $2.75 \pm 0.48$ & $2.40 \pm 0.28$ \\
\hline Iron, $\mathrm{mcg} / \mathrm{l}$ & $108.93 \pm 2.10$ & $109.17 \pm 1.66$ & $119.60 \pm 4.83$ & $112.53 \pm 3.29$ \\
\hline Copper, mg/l & $0.49 \pm 0.01$ & $0.60 \pm 0.01 * * *$ & $0.52 \pm 0.02 * *$ & $0.59 \pm 0.02 * * *$ \\
\hline Zinc, mg/l & $2.67 \pm 0.24$ & $2.64 \pm 0.11$ & $2.28 \pm 0.07$ & $2.15 \pm 0.02 *$ \\
\hline Cobalt, $\mathrm{mg} / 1$ & 0.002 & 0.002 & 0.002 & 0.004 \\
\hline Manganese, $\mathrm{mg} / \mathrm{l}$ & 0.02 & 0.02 & 0.02 & 0.02 \\
\hline \multicolumn{5}{|c|}{ last $1 / 3$ of gestation } \\
\hline Calcium, $\mathrm{mmol} / 1$ & $2.38 \pm 0.02$ & $2.50 \pm 0.04$ & $2.65 \pm 0.06$ & $2.52 \pm 0.04$ \\
\hline Phosphorus, $\mathrm{mmol} / 1$ & $2.26 \pm 0.05$ & $2.06 \pm 0.04 * *$ & $2.14 \pm 0.01 *$ & $2.35 \pm 0.03$ \\
\hline Iron, $\mathrm{mcg} / \mathrm{l}$ & $108.07 \pm 1.47$ & $119.43 \pm 8.41$ & $111.80 \pm 4.43$ & $118.20 \pm 8.25$ \\
\hline Copper, mg/l & $0.54 \pm 0.01$ & $0.54 \pm 0.03$ & $0.57 \pm 0.03$ & $0.55 \pm 0.02$ \\
\hline Zinc, mg/1 & $2.78 \pm 0.43$ & $2.46 \pm 0.29$ & $2.24 \pm 0.11$ & $2.31 \pm 0.04$ \\
\hline Cobalt, mg/l & 0.007 & 0.004 & 0.003 & 0.002 \\
\hline Manganese, $\mathrm{mg} / \mathrm{l}$ & 0.06 & 0.04 & 0.03 & 0.03 \\
\hline
\end{tabular}

During the entire period of gestation, sows of group II and III in comparison with the control group I have a tendency to increase blood calcium. With positive dynamics of phosphorus assimilation in the first two-thirds of gestation in animals of group III and IV, before farrowing in group II and III, they decreased by 8.8 and $5.3 \%(\mathrm{P} \leq 0.05-0.01)$, respectively. The observed tendency of iron increase in the blood of sows of all groups is explained by an increase in hemoglobin in whole blood, and consequently the respiratory function of cells with redox processes of metabolism. The addition of copper as part of the mineral complex most clearly increased its concentration in the blood of sows of the experimental groups in the first two-thirds of gestation. As a result, the quantitative difference in group II compared to group I was $22.4 \%(\mathrm{P} \leq 0.001)$, in group III $-6.1 \%$ $(\mathrm{P} \leq 0.01)$ and in group IV $-20.4 \%(\mathrm{P} \leq 0.001)$. In the second half of pregnancy, the concentration of this element in all groups was the same.

The decrease in zinc in the blood of animals of the experimental groups in comparison with the control group is explained by its higher use by the pancreas in carbohydrate metabolism, which is confirmed by the indications of glucose in whole blood.

With an increase in metabolic processes in the body of pregnant animals in the last third of gestation, the level of mineral elements such as cobalt and manganese in the blood also changes. The amount of cobalt in the experimental groups in comparison with the control group decreased by 1.8-3.5 times, and manganese - by 1.5-2.0 times.

The above-described changes in the metabolism of pregnant sows under the influence of the studied feed additives had a certain effect on their reproductive functions, the results of which are shown in table 5 .

Table 5. Reproductive functions of sows $\left(X \pm m_{x}, n=15\right)$

\begin{tabular}{|l|c|c|c|c|}
\hline \multirow{2}{*}{ Indicator } & \multicolumn{4}{|c|}{ Group } \\
\cline { 2 - 5 } & I & II & III & IV \\
\hline $\begin{array}{l}\text { Multiple pregnancy, head: - } \\
\text { total }\end{array}$ & $11.8 \pm 0.85$ & $13.0 \pm 0.82$ & $14.4 \pm 0.51^{* *}$ & $14.0 \pm 0.48^{*}$ \\
\hline - including live ones & $9.9 \pm 0.61$ & $10.6 \pm 0.62$ & $11.8 \pm 0.45^{* *}$ & $11.4 \pm 0.33^{* *}$ \\
\hline Heavy litter, kg & $1.36 \pm 0.05$ & $1.34 \pm 0.05$ & $1.26 \pm 0.03$ & $1.29 \pm 0.03$ \\
\hline $\begin{array}{l}\text { Live weight of one young pig } \\
\text { in 30 days, kg }\end{array}$ & $8.24 \pm 0.37$ & $7.25 \pm 0.23^{*}$ & $7.56 \pm 0.26$ & $8.79 \pm 0.26$ \\
\hline
\end{tabular}




\begin{tabular}{|l|c|c|c|c|}
\hline Live weight gain, kg & $6.90 \pm 0.37$ & $5.91 \pm 0.25^{*}$ & $6.30 \pm 0.25$ & $7.51 \pm 0.27$ \\
\hline Nest live weight, kg: & & & & \\
\hline - в 30 cyток & $85.41 \pm 4.12$ & $73.81 \pm 3.08^{*}$ & $78.11 \pm 3.44$ & $92.48 \pm 3.14$ \\
\hline Nest live weight gain, kg & 69.68 & 56.83 & 59.84 & 74.57 \\
\hline $\begin{array}{l}\text { Number of young pigs in a } \\
\text { group, head: }\end{array}$ & & & & \\
\hline - at birth & 149 & 159 & 177 & 171 \\
\hline - at weaning & 127 & 132 & 144 & 158 \\
\hline Safety, \% & 85.2 & 83.0 & 81.4 & 92.4 \\
\hline
\end{tabular}

The inclusion of folic acid with trace elements in the diet of group II in comparison with the control group I allowed to increase the total number of newborn young pigs in the nest by $10.2 \%$, the addition of Hexavit with trace elements (group III) - by $22.0 \%$ ( $\mathrm{P} \leq 0.01$ ), with their complex use in group IV - by $18.6 \%(\mathrm{P} \leq 0.05)$, including live young pigs - by $7.1 \%, 19.2$ and $15.2 \%(\mathrm{P} \leq 0.01)$. At the same time, the heavy litter young pigs in the nest did not have significant differences.

The lower live weight of young pigs at the age of one month in sows of group II and III can be explained by their low milk production and a large number of heads at suckling. At the same time, the complex addition of all the ingredients in the diet of group IV sows in comparison with the control group made it possible to get an increase in live weight by weaning age by $0.61 \mathrm{~kg}$, or $8.8 \%$ more, and in the whole group by $7.07 \mathrm{~kg}$.

The inclusion of a complex supplement in the diet of sows of the suckling period ensured the safety of the young pig livestock for weaning at the level of $92.4 \%$, which was higher than the control group by $7.2 \%$, while group II was inferior to group I by $2.2 \%$, group III - by $3.8 \%$.

Calculation of the economic efficiency of the use of tested feed additives in the diet of pregnant and suckling sows by the number of reared young pigs of weaning age allows to conclude the feasibility of their use. Accounting for actually fed feed for the period of scientific and economic experience and getting young pigs for weaning are presented in table 6.

Table 6. Feed costs for the production of weaned young pigs (per 1 sow)

\begin{tabular}{|l|c|c|c|c|}
\hline \multirow{2}{*}{ Indicator } & \multicolumn{4}{|c|}{ Group } \\
\cline { 2 - 5 } & I & II & III & IV \\
\hline $\begin{array}{l}\text { Fed during the accounting } \\
\text { period: - feed, kg }\end{array}$ & 517.80 & 523.12 & 528.44 & 523.12 \\
\hline - EFU, MJ & 642.20 & 649.65 & 657.10 & 649.65 \\
\hline - crude protein, kg for & 75.90 & 76.86 & 77.82 & 76.86 \\
\hline - digestible protein, kg pigs young & 53.89 & 56.81 & 59.81 & 59.92 \\
\hline $\begin{array}{l}\text { Received yeaning, head } \\
\text { went on 1 weaned young pig: }\end{array}$ & 8.8 & 9.6 & 10.5 \\
\hline Spent & 75.85 & 73.82 & 68.45 & 61.68 \\
\hline - EFU, MJ & 100.0 & 97.3 & 90.2 & 81.3 \\
\hline in \% to group I & 6.36 & 6.46 & 6.23 & 5.69 \\
\hline - digestible protein, kg & 100.0 & 101.4 & 97.9 & 89.4 \\
\hline in \% to group I
\end{tabular}

Sows of the control and experimental groups received almost the same rate of compound feed and nutrients during the gestation period, with the exception of the difference in the number of young pigs under the sow. As a result, $75.85 \mathrm{EFU}$ and $6.36 \mathrm{~kg}$ of digestible protein were spent on one reared pig in the control group, while in group II, EFU costs decreased by $2.7 \%$, but the amount of digestible protein increased by $1.4 \%$, in group III and IV, energy and protein costs were lower than in the control group by 9.8 and $2.1 \%, 18.7$ and $10.6 \%$, respectively. 


\section{Conclusions and discussions}

Consequently, the use of biologically active substances in the diet of pregnant and suckling sows directly affects the metabolism, and, consequently, the trophism of developing fetus. Vitamins and trace elements, participating in many metabolic processes has generated a higher prolificacy of sows, growth and safety of young pigs in the suckling period of cultivation. The data obtained are consistent with previous research conducted by scientists of educational and research institutes in the country $[1,2,4,5,8,9]$. The greatest effect of including the studied feed additives in the diet is the use of folic acid throughout the gestation period as a stimulator of the reproductive functions of the breeding stock, as well as biogenic microelements against an increased background of vitamin nutrition of sows, which allowed to increase the multiplicity and safety of livestock in the group.

Based on the conducted research, the following conclusions can be drawn. Complete feed for gestating and lactating sows containing normalized amounts of minerals and vitamins are not always consistent with the needs of animals and requires an increasing rate of nutrients supply according to climatic zone, chemical form of mineral salts, and compatibility of the components of the complete feed. The most accurate method of monitoring the provision of sows with the required amount of nutrients is a periodic morpho-biochemical study of blood and correction of the diet on its basis. It is advisable to use folic acid as part of the diet, as well as a complex of biogenic microelements with an increase in the rate of vitamin intake, in the form of a complex preparation Hexavit.

\section{References}

1. S.V. Burtseva, I.A. Pushkarev, Bulletin of the Altai SAU, 4(162), 116-120 (2018)

2. S.G. Grigoryev, A.O. Mullakaev, R.A. Shukanov, A.A. Shukanov, Formation and development of functional systems in productive animals when using biogenic substances in the biogeochemical conditions of the Volga region and the South-East of Chuvashia (FSEI HPO Chuvash SPU n.a. I. Ya. Yakovlev, Cheboksary, 2008)

3. M.I. Klementyev, M.G. Chabaev, R.V. Nekrasov, Organic selenium compounds in the diets of pregnant and lactating sows, Scientific support of animal husbandry development in the Russian Federation: Col. of mat. of the International Scientific and Practical Conference dedicated to the 90th anniversary of VIZh n.a. Academician L.K., (Ernst., Dubrovitsy, 2019)

4. E.N. Lubina, Scientific notes of the Kazan State Academy of Veterinary Medicine n.a. N.E. Bauman, 205, 130-134 (2011)

5. R.V. Nekrasov, M.G. Chabaev, N.V. Bogolyubova, E.Yu. Tsis, R.A. Rykov, A.A. Semenova, Agrarian science, 10, 49-55 (2019)

6. A.A. Ochinnikov, D.V. Chikotin, Changes in hematological parameters under the influence of feed additives, Agrarian science to agriculture: Mat. XII Intern. Scientific and Practical Conf. of the Altai SAU. Barnaul, 171-173 (2017)

7. A.A. Ochinnikov, D.V. Chikotin, Effect of feed additives on the digestibility of nutrients in the diet, Innovative activity in the modernization of the agro-industrial complex: Mat. of the VIII International Conference of students, postgraduates and young scientists of the Kursk SAA, (Kursk, 2016)

8. N.A. Pozdnyakova, A.L. Zasypkin, Bulletin of the Kurgan SAA., 3(27), 48-51 (2018)

9. V.A. Solyanik, Animal husbandry and veterinary science, 3(34), 14-18, (2019)

10. I.I. Stetsenko, N.A. Lubin, T.M. Shlenkina, Bulletin of the Ulyanovsk State Agricultural Academy, 4, 57-64 (2011) 
11. V.I. Fisinin, S.A. Miroshnikov, E.A. Sizova, A.S. Ushakov, E.P. Miroshnikova, World's Poultry Science Journal, 74(3), 523-540 (2018)

12. J.A. Greenberg et al., Folic Acid Supplementaion and Pregnancy: More Than Just Neural Tube Defect Prevention. - Rev Obstet Gynecol., 4(2), 52-59 (2011)

13. M. Lucock, Mol Genet Metab, 71(1-2), 121-138 (2000)

14. K. Pietrzik et al., Clin Pharmacok, 49(8), 535-548 (2010)

15. M.Q. Wang, Journal of Animal Physiology and Animal Nutrition, 520-525 (2008) 